\title{
Clinical Outcomes of Suspected Ischemic Myelopathy in Cats
}

\author{
Yuya NAKAMOTO ${ }^{1,2,3) *}$, Tsuyoshi OZAWA ${ }^{1,2)}$, Tadahisa MASHITA' ${ }^{1,4)}$, Masashi MITSUDA ${ }^{5)}$, Kengo KATAKABE ${ }^{1,6)}$ \\ and Munekazu NAKAICHI ${ }^{3,7)}$ \\ ${ }^{1)}$ Kyoto Animal Medical Center, 10-1, 1 Nishinoguchi-Sayama, Kumiyamacho, Kuzegun, Kyoto 613-0034, ${ }^{2)}$ Ozawa Animal Hospital, 4 \\ Niban-Uji, Uji, Kyoto 611-0021, ${ }^{3)}$ The United Graduate School of Veterinary Science, Yamaguchi University, 1677-1 Yoshida, \\ Yamaguchi 753-8515, ${ }^{4)}$ Maizuru Animal Medical Center, 8-22 Hama-cho, Maizuru, Kyoto 625-0037, ${ }^{5}$ Nodayama Animal Hospital, \\ 1058-1 Nodayama-cho, Hikone, Shiga 522-0025, , Kusatsu Dog and Cat Hospital, 3-18-11 Nomura, Kusatsu, Shiga 525-0027 and \\ ${ }^{7}$ Department of Veterinary Radiology, Faculty of Agriculture, Yamaguchi University, 1677-1 Yoshida, Yamaguchi 753-8515, Japan
}

(Received 24 March 2010/Accepted 28 July 2010/Published online in J-STAGE 11 August 2010)

ABSTRACT. Ischemic myelopathy is a disorder of acute onset that is characterized by nonprogressive paresis/plegia. Magnetic resonance imaging (MRI) is particularly helpful in supporting the antemortem diagnosis of ischemic myelopathy. Cats, which were suspected to have ischemic myelopathy between 2005 and 2008, were reviewed retrospectively. The acute onset of nonprogressive and nonpainful myelopathy, the conduct of spine MRI, and the availability of complete medical records were included in the inclusion criteria. The presumptive diagnosis was based on medical history as well as clinical, cerebrospinal fluid, and MRI findings. Six cats met the inclusion criteria based on medical records that had been made for about 3 years, and had relatively good prognoses. The less number of patients with ischemic myelopathy has been reported in cats than in dogs. However, the number of cats with ischemic myelopathy in clinical settings appears to be greater than previously considered.

KEY WORDS: feline, ischemic myelopathy, magnetic resonance imaging.

Ischemic myelopathy is a disorder of acute onset that is characterized by nonprogressive, mono-, hemi-, or quadriparesis/plegia unless ascending or descending myelomalacia develops $[4,16]$. Ischemic myelopathy has been described in several species, including humans [7, 18, 20], dogs [2, 5, 8, 9, 17], horses [22], pigs [23], sheep [10], turkeys [21], and cats [1, 3, 6, 12-14, 19, 24, 25]. In humans, ischemic myelopathy may be caused by atherosclerosis, vasculitis, embolism, infection, surgery, or trauma [18]. In animals, the proposed etiologies include fibrocartilaginous embolism, thromboembolism, hypercoagulability, vasculopathy, septic embolization, and parasitic embolization [4, 16]. The definitive diagnosis of ischemic myelopathy requires histologic examination $[4,16]$. The antemortem suspicion of ischemic myelopathy is based on a complete medical history in addition to clinical symptoms with an acute onset of nonpainful, nonprogressive (after the first 24 $\mathrm{hr}$ ), and often asymmetric clinical signs. The potential etiologies of spinal lesions should be ruled out by performing radiographies, ultrasound examinations, cerebrospinal fluid (CSF) analyses, myelographies, computed tomographies, and magnetic resonance imaging (MRI) $[8,18]$. MRI is helpful in supporting the antemortem diagnosis of ischemic myelopathy because the procedure, in addition to excluding the other etiologies of myelopathy, may reveal signal intensity changes that are compatible with ischemic myelopathy $[2,7,9,11,17,20]$. The aim of this study was to examine the clinical outcomes of cats with suspected ischemic myelopathy.

\footnotetext{
* Correspondence to: NaKamoto, Y., Ozawa Animal Hospital, 4 Niban-Uji, Uji, Kyoto 611-0021, Japan.

e-mail: dioinvalhalla@yahoo.co.jp
}

The medical records and MR images of cats that presented with suspected ischemic myelopathy at the Kyoto Animal Medical Center between June 1, 2005 and February 28,2008 were reviewed. The inclusion criteria were an acute $(<24 \mathrm{hr})$ onset of nonprogressive and nonpainful myelopathy, the 0.3 Tesla MRI of the spine performed within 14 days after onset, and complete medical records. The presumptive diagnoses were based on medical histories as well as clinical, CSF, and MRI findings consistent with those previously reported for nontraumatic ischemic myelopathy $[1-3,5-9,12-14,17-20,24,25]$.

The following information was retrieved from the medical records: age; sex; breed; body weight; physical activity before onset of signs; onset and course of clinical signs; general physical and neurologic examination findings; complete blood count (CBC) results; serum biochemistry profile; thoracic and abdominal radiographs; thoracic and abdominal ultrasound examinations; CSF analyses; and MR images.

For the MRI analyses, the patients were premedicated with midazolam (Dormicum; Astellas Pharma, Tokyo, Japan). After the induction of anesthesia and intubation with propofol (Propofol Injection 1\% "F"; Fuji Pharma, Toyama, Japan), the anesthesia was maintained with isoflurane (ISOFLU; Dainippon Sumitomo Pharma, Osaka, Japan). MRI was performed with a Hitachi AIRIS-II Comfort scanner (magnetic field strength: 0.3 Tesla; Hitachi Medical Systems, Tokyo, Japan). T2-weighted images (T2WIs), T1-weighted images (T1WIs), and postcontrast T1WIs by the intravenous injection of meglumine gadopentate (Magnevist; Bayer Health Care, Osaka, Japan) 93.8 mg/ $\mathrm{kg}$ were obtained in the sagittal and transverse planes. The 
images were evaluated for evidence of spinal cord compression and parenchymal lesions.

The MRI diagnosis of suspected ischemic myelopathy was made based on the imaging criteria for suspected/definite ischemic myelopathy in humans [7, 20], dogs [2, 9, 17], and cats [12-14]. These criteria included the presence of intramedullary lesions that involved hyperintense spinal cord gray matter on T2WIs, hypointense to isointense spinal cord gray matter on T1WIs, and unenhanced to slightly enhanced spinal cord gray matter on postcontrast T1WIs. Cats with evidence of intervertebral disk protrusion into the intervertebral disk spaces directly beneath or immediately cranial or caudal to the spinal cord lesion and cats with evidence of a lesion occupying the spaces of the spinal cord other than the intervertebral disks on MRI scans were excluded $[11,15]$.

Cats were evaluated throughout the clinical course from the time of admission to the referral center until gait recovery. Gait recovery was defined as the restoration by the animal of the ability to walk by itself while applying burden on the affected $\operatorname{limb}(\mathrm{s})$. The normal postural reactions during the neurological examinations performed by the clinician in charge were also considered as part of the definition for gait recovery.

Based on the presumptive diagnosis, the owner was instructed to perform three 15-min sessions of physiotherapies (e.g., induced flexion reflex, muscle massage, and stretches) daily. Medications were not prescribed for any of the patients.

Six cats met the inclusion criteria at the Kyoto Animal Medical Center between June 1, 2005 and February 28, 2008. The patient profiles are shown in Table 1. The mean age of the patients was about 11 years (range: 2 years and 9 months to 16 years and 5 months). Males and females were present in equal numbers, and all the females and one male were neutered. The mean body weight was $4.6 \mathrm{~kg}$ (range: $3.0-5.5 \mathrm{~kg}$ ). The breeds of the cats were the Domestic Shorthair $(n=5)$ and the Persian $(n=1)$. The limbic symptoms were quadriparesis in 4 cats and paresis of pelvic limbs in 2 cats. The mean lapse time before referral to the Kyoto Animal Medical Center after the onset of clinical symptoms was 4 days (range: 1-8 days). Hematologic, serum biochemical, radiographic, and ultrasound examinations were normal in all cats, expect for increased concentrations of blood urea nitrogen $(60 \mathrm{mg} / \mathrm{d} l$; reference interval: $16-36$ $\mathrm{mg} / \mathrm{d} l)$ and creatinine $(3.8 \mathrm{mg} / \mathrm{d} l$; reference interval: $0.8-2.4$ $\mathrm{mg} / \mathrm{d} l$ ) in one cat (cat No. 1). A CSF analysis was performed in only one cat (cat No. 7). The CSF, collected by lumbar puncture, was sent to an external clinical laboratory for analysis. The analysis revealed a negative Pandy's test (reference value: negative), 2 cells/ $\mu l$ (reference value: $<5$ cells $/ \mu l$ ) in cell count, and $11 \mathrm{mg} / \mathrm{d} l$ (reference value: $10-40$ $\mathrm{mg} / \mathrm{d} l)$ in total protein. The differential cell count revealed $100 \%$ small nonreactive lymphocytes.

Lesions with signals of abnormal intensities developed in the C1-5 (3 cats), C6-T2 (2 cats), T3-L3 (0 cat) and L4-S3 (1 cat) regions of the spinal cord. Asymmetrical lesions were detected in 4 cats (right side, 1 cat; left side, 3 cats). In 2 cats, the lesions were centrally located in the spinal cord and demonstrated no specific asymmetry on MRI scans (Fig. 1).

The neurologic deficits improved within 2 weeks, 3 weeks, and 1 month of treatment in 4 cats ( 3 cats with the C1-5 lesions and 1 cat with the C6-T2 lesion), 1 cat (with the C6-T2 lesions) and 1 cat (with the L4-S3 lesions), respectively. All the cats survived for at least 20 months after treatment onset, without relapses in symptoms.

In dogs, many cases of ischemic myelopathy have been reported $[2,5,8,9,17]$, whereas only 9 reports (14 total cases) have been documented in cats $[1,3,6,12-14,19,24$, 25]. We considered that differences in the incidences of ischemic myelopathy between cats and dogs reflect the following facts: the lower incidence of intervertebral disk disease in cats than in dogs $[11,15]$; and the most common cause of ischemic myelopathy is fibrocartilaginous embolism that presents histochemical properties identical to those of the nucleus pulposus of the intervertebral disk [16].

For the definite diagnosis of ischemic myelopathy, the confirmation of an embolus in the spinal cord lesion by pathological examination is mandatory $[4,16]$. However, the histopathological examination of the lesions was not performed in our cats while they were alive. MRI is helpful in supporting the antemortem diagnosis of ischemic myelopathy because the procedure, in addition to excluding the other etiologies of myelopathy, may reveal signal intensity changes that are compatible with ischemic myelopathy $[2,7$,

Table 1. Cat profiles

\begin{tabular}{|c|c|c|c|c|c|c|c|c|c|c|}
\hline $\begin{array}{l}\text { Cat } \\
\text { No. }\end{array}$ & Breed & Age & Sex & $\begin{array}{l}\text { Body } \\
\text { weight } \\
\text { (kg) }\end{array}$ & $\begin{array}{c}\text { Date from } \\
\text { onset to } \\
\text { MRI }\end{array}$ & $\begin{array}{l}\text { Date of } \\
\text { ambulation } \\
\text { recovery }\end{array}$ & $\begin{array}{l}\text { Impairment } \\
\text { of motor } \\
\text { function }\end{array}$ & Deep pain & $\begin{array}{c}\text { Spinal cord } \\
\text { lesions on } \\
\text { MRI scans }\end{array}$ & $\begin{array}{l}\text { Location of the } \\
\text { lesion on MRI } \\
\text { scans }\end{array}$ \\
\hline 1 & $\mathrm{PC}$ & $16 \mathrm{yr} 5 \mathrm{mth}$ & Spayed female & 3.0 & 4 & 10 & Quadriparesis & + & $\mathrm{C} 2-3$ & Centrally \\
\hline 2 & DSH & $13 \mathrm{yr}$ & Spayed female & 4.0 & 5 & 13 & $\begin{array}{l}\text { Paresis (PLs) } \\
\text { Left side HS }\end{array}$ & + & $\mathrm{C} 7-\mathrm{T} 1$ & Left side \\
\hline 3 & DSH & $8 \mathrm{yr} 1 \mathrm{mth}$ & Spayed female & 5.4 & 4 & 27 & Paresis (PLs) & + & L5-6 & Left side \\
\hline 4 & DSH & $13 \mathrm{yr}$ & Castrated male & 5.5 & 1 & 7 & Quadriparesis & + & C3-4 & Centrally \\
\hline 5 & DSH & $12 \mathrm{yr}$ & Castrated male & 4.4 & 8 & 21 & Quadriparesis & - & C7-T1 & Left side \\
\hline 6 & DSH & $2 \mathrm{yr} 9 \mathrm{mth}$ & Male & 5.3 & 2 & 10 & Quadriparesis & + & C1-2 & Right side \\
\hline
\end{tabular}

PC, Persian cat; DSH, domestic shorthaired cat; yr, years; mth, months; PLs, pelvic limbs; HS, Horner syndrome; +, existence; -, loss; MRI, magnetic resonance imaging; $\mathrm{C}$, cervical; $\mathrm{T}$, thoracic; $\mathrm{L}$, lumbar. 


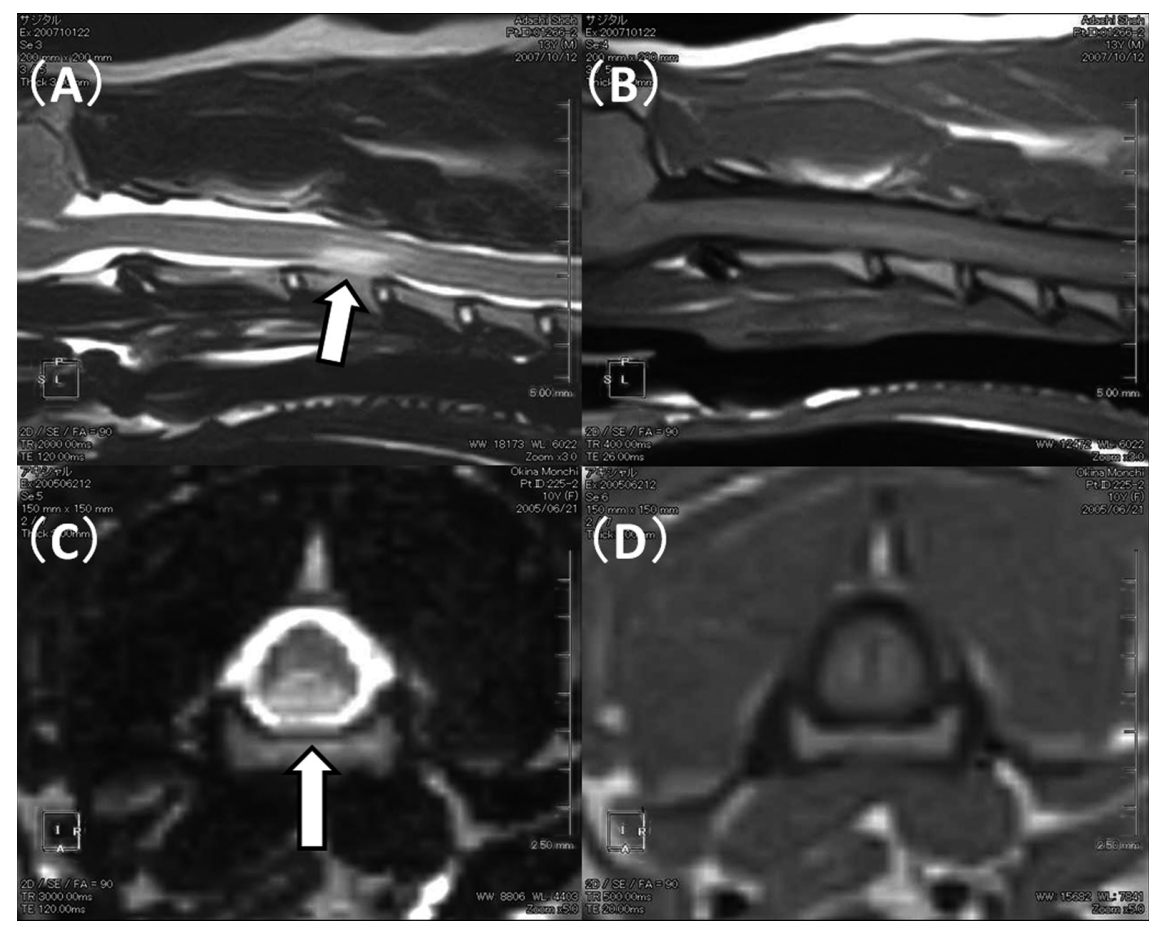

Fig. 1. MRI scans of the cervical spine of cat No. 4. (A) Sagittal plane of the spinal cord at its midline on a T2-weighted image (T2WI). The spinal cord lesion showing hyperintense signals (arrow). (B) Sagittal plane of the spinal cord at its midline on a T1-weighted image (T1WI). The spinal cord lesion showing isointense signals. (C) Transverse section of the C3-4 vertebrae on a T2WI. The spinal cord lesion showing hyperintense signals (arrow) is centrally located. (D) Transverse section of the C3-4 vertebrae on a T1WI. The spinal cord lesion showing isointense signals.

$9,11,17,20]$. In humans, however, the affected site may not show any abnormality on MRI scans [7, 18, 20]. Based on these reasons, we should keep in mind the possibility that MRI does not allow the definite diagnosis of ischemic myelopathy in patients.

Regarding the infarct site, canine ischemic myelopathy occurs at the C6-T2 and L4-S3 regions at a high rate [4, 5, 16]. Previous studies on feline ischemic myelopathy have reported lesions in the $\mathrm{C} 1-5$ and $\mathrm{C} 6-\mathrm{T} 2$ regions of the spinal cord [1, 3, 6, 12-14, 19, 24, 25]. In this study, many lesions were also located in the C1-5 and C6-T2 regions of the spinal cord. This may suggest that the cervical spinal cord is the predilection site for ischemic myelopathy in cats.

The prognosis is poor in dogs with lesions at C6-T2 and L4-S3 and with a loss of deep pain sensation [4, 16]. The prognosis has not been investigated in cats because the number of reported cases of ischemic myelopathy is small. In previous studies, 8 out of 14 cats were euthanized at an early stage of the disease, and only 6 cats survived [1, 3, 6, 12-14, $19,24,25]$. The lesions were located at the C1-5 level of the spinal cord in 2 of the 6 surviving cats, and 25 days to 6 weeks were required for the improvement of symptoms [12, 14]. In 3 of the surviving cats, the lesions developed in the C6-T2 region of the spinal cord and 2 weeks were required for the improvement of symptoms $[6,12,13]$. In the remaining surviving cat, the lesion was located in the T3-L3 region of the spinal cord and the symptoms improved within 2 days [13]. In our study, the neurologic deficits improved 9 and 16 days on average after onset in cats with the C1-5 and C6-T2 lesions, respectively. The neurologic deficits recovered 27 days after onset in the L4-S3 lesions. Therefore, the infarct site may be not related to the prognosis in cats. In one previous report, 3 out of 4 cats with a loss of deep pain sensation showed no improvement of clinical symptoms and were subjected to euthanasia [13]. In our report, 1 cat with a loss of deep pain sensation showed improvement of clinical symptoms. The relationship between the existence of deep pain sensation and prognosis must be further investigated. The prognosis of feline ischemic myelopathy is unclear regarding many aspects of the disorder. In cats, there are few case reports of this condition and most patients with ischemic myelopathy are euthanized at an early stage. Consequently, the relationship between the site of the lesion and prognosis has not been determined. The accumulation of cases may advance investigations concerning the prognosis of ischemic myelopathy in cats.

In conclusion, feline patients with clinical symptoms and MRI findings in this study that were diagnosed with suspected ischemic myelopathy had relatively good prognoses. 
In dogs, many cases with ischemic myelopathy have been reported. In cats, however, only 9 studies have reported 14 cases in total $[1,3,6,12-14,19,24,25]$. In this study, 6 cats with suspected ischemic myelopathy were diagnosed in the short term. Therefore, the less number of patients with ischemic myelopathy has been reported in cats than in dogs. However, the number of cats with ischemic myelopathy in clinical settings appears to be greater than previously considered.

\section{REFERENCES}

1. Abramson, C. J., Platt, S. R. and Stedman, N. L. 2002. Tetraparesis in a cat with fibrocartilaginous emboli. J. Am. Anim. Hosp. Assoc. 38: 153-156.

2. Abramson, C. J., Garosi, L., Platt, S. R., Dennis, R. and McConnell, J. F. 2005. Magnetic resonance imaging appearance of suspected ischemic myelopathy in dogs. Vet. Radiol. Ultrasound 46: 225-229.

3. Bischel, P., Vandevelde, M. and Lang, J. 1984. L'infarctusde la moelle epiniere a la suite d'embolies fibrocartilagineuses chez le chien et la chat. Schweiz. Arc. Tierheilkd. 126: 387-397 (in French).

4. Cauzinille, L. 2000. Fibrocartilaginous embolism in dogs. Vet. Clin. North Am. Small Anim. Pract. 30: 155-167.

5. Cauzinille, L. and Kornegay, J. N. 1996. Fibrocartilaginous embolism of the spinal cord in dogs: review of 36 histologically confirmed cases and retrospective study of 26 suspected cases. J. Vet. Intern. Med. 10: 241-245.

6. Coradini, M., Johnstone, I., Filippich, L. J. and Armit, S. 2005. Suspected fibrocartilaginous embolism in a cat. Aust. Vet. J. 83: $550-551$.

7. Duprez, T. P., Danvoye, L., Hernalsteen, D., Cosnard, G., Sindic, C. J. and Godfraind, C. 2005. Fibrocartilaginous embolization to the spinal cord: serial MR imaging monitoring and pathologic study. AJNR Am. J. Neuroradiol. 26: 496-501.

8. Gandini, S., Cizinauskas, S., Lang, J., Fatzer, R. and Jaggy, A. 2003. Fibrocartilaginous embolism in 75 dogs: clinical findings and factors influencing the recovery rate. J. Small Anim. Pract. 44: 76-80.

9. Hawthorne, J. C., Wallace, L. J., Fenner, W. R. and Waters, D. J. 2001. Fibrocartilaginous embolic myelopathy in miniature schnauzers. J. Am. Anim. Hosp. Assoc. 37: 374-383.

10. Jeffery, M. and Wells, G. A. 1986. Multifocal ischemic encephalomyelopathy associated with fibrocartilaginous emboli in the lamb. Neuropathol. Appl. Neurobiol. 12: 231-
244.

11. Knipe, M. F., Vernau, K. M., Hornof, W. J. and LeCouteur, R. A. 2001. Intervertebral disc extrusion in six cats. J. Feline. Med. Surg. 3: 161-168.

12. MacKey, A. D., Rusbridge, C., Sparkes, A. H. and Platt, S. R. 2005. MRI characteristics of suspected acute spinal cord infarction in two cats, and a review of the literature. J. Feline Med. Surg. 7: 101-107.

13. Mikszewski, J. S., Van Winkle, T. J. and Troxel, M. T. 2006. Fibrocartilaginous embolic myelopathy in five cats. $\mathrm{J}$. Am. Anim. Hosp. Assoc. 42: 226-233.

14. Mitsuda, M., Yoshioka, H., Akagi, Y., Mashita, T. and Uchida, K. 2007. Suspected fibrocartilaginous embolism in a cat with spinal infarction. J. Anim. Clin. Med. 16: 115-118 (in Japanese with English summary).

15. Munana, K. R., Olby, N. J., Sharp, N. J. and Skeen, T. M. 2001. Intervertebral disc disease in 10 cats. J. Am. Anim. Hosp. Assoc. 37: 384-389.

16. Neer, T. M. 1992. Fibrocartilaginous emboli. Vet. Clin. North Am. Small Anim. Pract. 22: 1017-1026.

17. Risio, L. D., Adams, V., Dennis, R., McConnell, F. and Platt, S. 2007. Magnetic resonance imaging findings and clinical associations in 52 dogs with suspected ischemic myelopathy. $J$. Vet. Intern. Med. 21: 1290-1298.

18. Sandson, T. A. and Friedman, J. H. 1989. Spinal cord infarction: report of 8 cases and review of the literature. Medicine (Baltimore) 68: 282-292.

19. Scotte, H. W. and O'Leary, M. T. 1996. Fibrocartilaginous embolism in a cat. J. Small Anim. Pract. 37: 228-231.

20. Simonson, T. M. and Yuh, W. T. 1996. Stroke and cerebral ischemia. pp. 767-786. In: Clinical Magnetic Resonance Imaging, 2nd ed. (Edelman, R. R., Zlatkin, M. B. and Hesselink, J. R. eds.), Saunders, Philadelphia.

21. Stedman, N. L., Brown, T. P. and Rowland, G. N. 1998. Intravascular cartilaginous in a tayra (Eira Barbara): a case report. $J$. Zoo Wildl. Med. 29: 470-473.

22. Taylor, H. W., Vandevelde, M. and Firth, E. C. 1977. Ischemic myelopathy by fibrocartilaginous emboli in a horse. Vet. Pathol. 14: 479-481.

23. Tessaro, S. V., Doige, C. E. and Rhodes, C. S. 1983. Posterior paralysis due to fibrocartilaginous embolism in two weaner pigs. Can. J. Comp. Med. 47: 124-126.

24. Turner, P. V., Percy, D. H. and Allyson, K. 1995. Fibrocartilaginous embolic myelopathy in a cat. Can. Vet. J. 36: 712 713.

25. Zaki, F. A., Prata, R. G. and Werner, L. L. 1976. Necrotizing myelopathy in a cat. J. Am. Vet. Med. Assoc. 169: 228-229. 